\title{
Hesitação/recusa vacinal: um assunto em pauta - Editorial
}

\author{
Vaccine hesitancy/refusal: a current issue - Editorial
}

Eleonor G. Lago (D)

Editora da Scientia Medica

Como citar este artigo (How to cite this article):

Lago EG. Hesitação/recusa vacinal: um assunto em pauta - Editorial (Vaccine hesitancy/refusal: a current issue - Editorial). Sci Med. 2018;28(4):ID32808. DOI: 10.15448/1980-6108.2018.4.32808

DESCRITORES: recusa de vacinas; hesitação vacinal; movimento antivacina; grupos contra vacinação; programas de imunização; relação médico-paciente.

$\mathrm{E}$ m 1998, o conceituado periódico britânico The Lancet publicou um relato que associava casos de autismo e doença inflamatória intestinal com a vacina tríplice viral (contra sarampo, caxumba e rubéola). O artigo caiu como uma bomba no meio científico e, consecutivamente, entre o público leigo. Decorrido algum tempo, a contraindicação dos médicos e/ou a recusa dos pais em aplicar em seus filhos essa vacina resultou em diversos surtos dessas viroses, com destaque para o sarampo, que pode apresentar grande morbidade e mortalidade. Posteriormente, estudos científicos e outras investigações revelaram os equívocos daquele artigo, que em 2010 foi retratado pelo próprio periódico $[1,2]$. Infelizmente, as consequências permaneceram e constituem uma das tantas motivações alegadas por grupos contrários à vacinação. Mas esse é apenas um dos episódios que vêm à nossa memória quando se trata do tema recusa vacinal.

O receio de efeitos adversos não é o único motivo pelo qual as pessoas rejeitam vacinas. A hesitação vacinal (pessoas que atrasam a vacinação ou recusam alguns tipos de vacinas) e a recusa vacinal (pessoas que rejeitam todo e qualquer tipo de vacina) podem ter várias motivações além da preocupação com a segurança, incluindo princípios filosóficos ou religiosos, aspectos socioculturais, baixa percepção do risco de doenças, questionamentos sobre a eficácia das vacinas e, até, orientação médica. Em alguns casos específicos, algumas vacinas podem de fato ser contraindicadas, mas eventualmente os médicos também seguem falsos princípios, acreditam em informações pseudocientíficas, ou são negligentes com a própria atualização [3-5]. Demonstrou-se, também, que em geral os pais gostariam de ter mais informações sobre as vacinas indicadas para os seus filhos [6].

A hesitação e a recusa vacinal não são fenômenos recentes, eles ocorrem desde os primórdios do advento das vacinas. No Brasil, por exemplo, é famoso o episódio "Revolta da Vacina", ocorrido no Rio de Janeiro em 1904, quando Oswaldo Cruz tornou obrigatória a vacina contra varíola, provocando a revolta da população. Segundo Guido Levi [3], entretanto, esse episódio foi mais devido à forma violenta com que a campanha foi realizada do que à vacina em si.

Nas últimas décadas, grupos radicais anti-vacinas vem ganhando força, principalmente em países de alta renda e em grupos com maior grau de instrução. Com o advento da internet e das redes sociais, a rápida difusão de falsas notícias é facilitada, ampliando a desinformação e trazendo como consequência epidemias de doenças imunopreveníveis e até risco de reintrodução de doenças já erradicadas. Nos Estados Unidos, por exemplo, muitos casos de sarampo ocorreram nos últimos anos em indivíduos intencionalmente não vacinados. No Brasil, houve decréscimo importante na cobertura vacinal entre 
2009 e 2017, o que é um dado preocupante. Entre outros motivos, a hesitação/recusa vacinal podem estar envolvidas nesse fenômeno, tendo em vista que o avanço de grupos contrários à vacinação tem sido observado em nosso País $[4,7,8]$.

No âmbito da ética, o princípio da autonomia é invocado para garantir o direito de uma pessoa recusar uma vacina por motivos não justificados cientificamente. Entretanto, a recusa vacinal pode ter consequências para a população a que o indivíduo pertence (por facilitar a persistência e disseminação do microorganismo) ou, no caso de pais que rejeitam a vacinação dos seus filhos, o princípio da não maleficência pode suplantar o da autonomia. A interpretação dos princípios éticos e a jurisprudência sobre o direito que os pais têm de decidir sobre a vacinação dos filhos variam entre os diversos países [9, 10]. No Brasil, uma lei federal e o Estatuto da Criança e do Adolescente determinam como compulsória a vacinação com base no Programa Nacional de Imunizações. Os pais ou responsáveis que negligenciam ou rejeitam a vacinação dos menores sob sua responsabilidade podem ser indiciados criminalmente por maus tratos, abandono ou omissão [5].

Outra questão que surge atualmente é sobre a atitude que deve ter um pediatra em relação aos pais que rejeitam imunizações de rotina para os seus filhos. Muitos pediatras recusam-se a atender essas famílias, argumentando que a falta de confiança dos pais pode prejudicar a relação médico-paciente, ou que as crianças não vacinadas podem ser um risco para as outras crianças na sala de espera $[5,11]$. Segundo o Código de Ética Médica brasileiro, o médico tem o direito de renunciar ao atendimento na presença de fatos que prejudiquem o bom relacionamento com o paciente ou seu representante legal [12]. Entretanto, o assunto é controverso, e outros acreditam que a atitude mais correta seria continuar prestando cuidados e tentando convencer os pais de que os benefícios das imunizações superam em muito os riscos $[5,11]$. Um estudo australiano identificou, também, dificuldades experimentadas por profissionais dos cuidados de saúde primários ao lidar com os pais que recusam a vacinação de seus filhos [13].

Embora o advento da vacinação infantil seja considerado o avanço científico do século XX de maior impacto na saúde pública [14], o assunto hesitação/recusa vacinal continua em pauta. A Organização Mundial da Saúde, reconhecendo o risco crescente desse problema e a necessidade de uma especial atenção, criou, dentro do Strategic Advisory Group of Experts (SAGE) on Immunization, um grupo de trabalho especialmente voltado ao assunto, o SAGE Working Group on Vaccine Hesitancy $(S A G E-W G)$ [15]. Uma revisão sistemática sobre estratégias de abordagem concluiu que o problema da hesitação/recusa vacinal é bastante complexo, não existindo uma estratégia única que seja capaz de resolvê-lo. Em geral, as estratégias múltiplas funcionam melhor do que as mais dirigidas, que teoricamente teriam uma melhor relação custo-benefício. Uma das maiores dificuldades das intervenções mais dirigidas é que muitas são delineadas a partir de uma abordagem baseada em premissas, e não em evidências [16]. Em geral os estudos concordam em que as estratégias mais indicadas são as educacionais, e que é importante ouvir as motivações dos pacientes para que a mensagem seja mais efetiva $[3-6,15,16]$

Recente relatório do $S A G E-W G$ concluiu que pesquisas sobre as razões e o grau de hesitação/recusa vacinal são importantes e podem ajudar a informar e refinar as abordagens a ser implementadas, tanto em níveis nacionais como subnacionais $[15,16]$. Dentro desse contexto, a Scientia Medica publica neste fascículo um levantamento realizado em uma região de Portugal, que identificou casos de recusa vacinal em todas as classes sociais e investigou os seus motivos [17].

\section{REFERÊNCIAS}

1. Wakefield AJ, Murch SH, Anthony A, Linnell J, Casson DM, Malik M, Berelowitz M, Dhillon AP, Thomson MA, Harvey P, Valentine A, Davies SE, Walker-Smith JA. Ileal-lymphoid-nodular hyperplasia, non-specific colitis, and pervasive developmental disorder in children. Lancet. 1998 Feb 28;351(9103):637-41. Erratum in: Lancet. 2004 Mar 6;363(9411):750. Retraction in: Lancet. 2010 Feb 6;375(9713):445. https://doi.org/10.1016/S0140-6736(97)11096-0

2. Eggertson L. Lancet retracts 12-year-old article linking autism to MMR vaccines. CMAJ. 2010 Mar 9;182(4):E199-200. https://doi.org/10.1503/cmaj.109-3179

3. Levi GC. Recusa de vacinas - causas e consequências. São Paulo: Segmento Farma; 2013.

4. Sato APS. Qual a importância da hesitação vacinal na queda das coberturas vacinais no Brasil? Rev Saúde Pública. 2018;52:96. 
5. Succi RCM. Vaccine refusal - what we need to know. J Pediatr (Rio J). 2018;94(6):574-81. https://doi.org/10.1016/j. jped.2018.01.008

6. Ames HM, Glenton C, Lewin S. Parents' and informal caregivers' views and experiences of communication about routine childhood vaccination: a synthesis of qualitative evidence. Cochrane Database Syst Rev. 2017 Feb 7;2:CD011787. https:// doi.org/10.1002/14651858.CD011787.pub2

7. Phadke VK, Bednarczyk RA, Salmon DA, Omer SB. Association Between Vaccine Refusal and Vaccine-Preventable Diseases in the United States: A Review of Measles and Pertussis. JAMA. 2016 Mar 15;315(11):1149-58. https://doi. org/10.1001/jama.2016.1353

8. Cambricoli F, Palhares I. Grupos contrários à vacinação avançam no País e preocupam Ministério da Saúde. Estadão Saúde [internet]. São Paulo; 2017 maio 21 [cited 2018 December]. Available from: https://saude.estadao.com.br/noticias/ geral,grupos-contrarios-a-vacinacao-avancam-no-pais-e-preocupam-ministerio-da-saude,70001800099

9. Santos P, Hespanhol A. Recusa vacinal - o ponto de vista ético. Rev Port Med Geral Fam. 2013;29:328-33. https://doi. org/10.32385/rpmgf.v29i5.11167

10. Grzybowski A, Patryn RK, Sak J, Zagaja A. Vaccination refusal. Autonomy and permitted coercion. Pathog Glob Health. 2017;111(4):200-5. https://doi.org/10.1080/20477724.2017.1322261

11. Alexander K, Lacy TA, Myers AL, Lantos JD. Should Pediatric Practices Have Policies to Not Care for Children With Vaccine-Hesitant Parents? Pediatrics. 2016;138(4): e20161597. https://doi.org/10.1542/peds.2016-1597

12. Conselho Federal de Medicina. Código de Ética Médica [internet]. Brasília-DF: 2018 [cited 2018 December]. Available from: http://www.portalmedico.org.br/novocodigo/integra.asp

13. Berry NJ, Henry A, Danchin M, Trevena LJ, Willaby HW, Leask J. When parents won't vaccinate their children: a qualitative investigation of Australian primary care providers' experiences. BMC Pediatr. 2017;17(1):19. https://doi. org/10.1186/s12887-017-0783-2

14. Centers for Disease Control and Prevention (CDC). Ten great public health achievements, 1900-1999: impact of vaccines universally recommended for children. MMWR. 1999;241:243-8.

15. World Health Organization. Weekly epidemiological record. Meeting of the Strategic Advisory Group of Experts on Immunization, October 2018 - Conclusions and recommendations [internet]. Geneva; 7 December 2018 [cited 2018 December]. Available from: http://apps.who.int/iris/bitstream/handle/10665/276544/WER9349.pdf?ua=1

16. Jarrett C, Wilson R, O’Leary M, Eckersberger E, Larson HJ; SAGE Working Group on Vaccine Hesitancy. Strategies for addressing vaccine hesitancy: a systematic review. Vaccine. 2015;33(34):4180-90. https://doi.org/10.1016/j. vaccine.2015.04.040

17. Fonseca MS, Varela MALN, Frutuoso A, Monteiro MFFRP. Recusa da vacinação em área urbana do norte de Portugal (Vaccine refusal in an urban area of northern Portugal). Sci Med. 2018;28(4):ID32152. http://doi.org/10.15448/19806108.2018.4.32152 